\section{Energy unit for global use}

SIR,-Very large powers of 10 occur in discussions of global energy, one example being the exajoule ( $10^{18}$ joule). As this number is larger than the number of seconds since the big bang $\left(\sim 5 \times 10^{17}\right)$ its size is difficult to appreciate, and a more intuitive unit is desirable.

Annual energy consumption is dimensionally power, and a good unit of power is a $60 \mathrm{~W}$ continuously burning light bulb. (One could make it a 100W bulb, but that is slightly less modest.)

Furthermore it makes sense to report Table 1 then expresses some important $2020 \mathrm{AD}$ are based on exhibit 19 of Bloodworth, I. J. et al., World Energy Demand to 2020, Executive Summary

(World Energy Conference, London, 1977).

The table shows the low average efficiency of photosynthesis: there is evidently scope for the development of high energy yielding crops.

To see the proposed unit in action, we ask to what extent the deserts of the world-a somewhat fuzzy concept - could supply world energy requirements by direct conversion of solar radiation (to

electricity, say). This is not a practical idea at present, but it is nonetheless important to have answers to such a question.

Assuming rather poor devices of $1 \%$ efficiency and an insolation at one tenth of the solar constant, one finds that the deserts would give an adequate yield for some decades to come (Table 2). Although there is in fact a great deal in hand at present, this advantage is being eroded.

The numbers for the energy expressed in these units and it is hoped that they carry an intuitive meaning. Yours faithfully, P. T. LANDSBERG

Department of Mathematics, University of Southampton, UK power per capita of the world population. energy flows : the figures for $2000 \mathrm{AD}$ and consumption are reasonably small when

\section{Military structure is off-target for science jobs}

SIR,-David Horrobin's military solution to the problems of job opportunities and job security ( 8 March, page 118 ) could more aptly be described as the final solution, for if implemented, his ideas would further encourage short-term grant funded work using basic scientists as technicians and assistants. The lack of prospects offered would simply discourage those wishing to enter research as a profession and would commit research to a supportive role in advancing the careers of teachers and, in medical research, clinicians. But what is the problem he is trying to solve? If it is the "unequivocal .. decline in research productivity between the years of 35 and 45 " then his efforts are misguided: I challenge the myth that research scientists are more susceptible to 'burning out' than any other professional group. The "decline in research productivity" reflects a combination of withdrawal of short-term funding support (experience comes expensive) and the scientist's disillusionment with the abysmal career prospects.

In his proposed career structure we would know by the age of $35-40$ whether or not we were suitable. If not, the alternative would be "the comfortable knowledge that they would have three years .... to plan a second career." Who on earth is going to employ a middle-aged scientist stigmatised by his so-called

"decline in research productivity." Like the universities, industry and government recruit largely at the graduate level and so event if they wished to pick up the able to do so. These proposals would also curb any independent thought, for the research worker would be continuously trying to please and impress the departmental 'Field Marshal' in the hope of being awarded another five years in academic 'casualties' they would not be

Table 1 Important energy flows (Earth averages)

\begin{tabular}{|c|c|c|}
\hline & $\begin{array}{l}60 \mathrm{~W} \text { bulbs } \\
\text { per capita }\end{array}$ & $\begin{array}{c}\text { Joules } \\
\text { per annum }\end{array}$ \\
\hline 1975 [World population $4 \times 10^{9}$ ] & & $15 \times 10^{19}$ \\
\hline Energy consumption & 33 & $\begin{array}{l}1.5 \times 10^{19} \\
2.5 \times 10^{20}\end{array}$ \\
\hline Photosynthesis yield & 410 & $3.1 \times 10^{21}$ \\
\hline Solar energy incident on Earth & 396,000 & $3.0 \times 10^{24}$ \\
\hline 2000 AD [World population $6 \times 10^{9}$ ] & 51 & $58 \times 10^{20}$ \\
\hline $\begin{array}{l}\text { Energy consumption } \\
2020 \text { AD [World population } 7 \times 10^{9} \text { ] }\end{array}$ & & \\
\hline Energy consumption & 76 & $1.0 \times 10^{21}$ \\
\hline
\end{tabular}

Table 2 Possible power yield from deserts

$\begin{array}{ccc}\text { Year } & \text { (60W bulbs p.c.) } & \text { (60W bulbs p.c.) } \\ 1975 & 141 & 33 \\ 2000 & 94 & 51 \\ 2020 & 81 & 76\end{array}$

Mean insolation is $135 \mathrm{Wm}^{-2}$; efficiency of devices $1 \%$. the despatches for efforts above and beyond the call of duty. Lastly, he resorts to the expedient of the gratuity payment. These always seem very generous at the time but, as many workers have recently found, the money is very soon spent, leaving the dole queue and senescence as the only feature on a bleak horizon.

Certainly scientists need a stimulus to work. But this should take the form of improved career prospects with adequate peer review by which effort, achievement and responsibility are rewarded; the game of Rusian roulette in which the trigger is pulled every five years is no basis for a profession.

\section{Yours faithfully,}

Mick Kadlubowski

Association of Researchers in

Medical Sciences,

London, UK.

\section{Sergei Kovalev: remember a colleague}

SIR,--Soviet biologist Sergei Kovalev is now in the fourth year of a seven-year term in a strict regime labour camp. He was sentenced in December 1975 for making known various violations of human rights by the Soviet state. Past support by scientists around the world has helped him to receive needed medical assistance and has ameliorated the harsh punishment given to him in the labour camp. Renewed efforts are now required to support him, lest he fade from the public eye and be left to the "mercy" of his jailers.

Scientists at the State University College at Buffalo and State University of New York at Buffalo have contributed funds and have purchased a journal subscription in Kovalev's name. It is sent regularly to him at his prison address. Colleagues at other institutions might well do likewise. Letters to Soviet authorities may also be helpful.

As spring approaches most of us in the northern hemisphere are going about our research and teaching and sharing the love of our families. Let us remind ourselves of our colleague, Sergei Kovalev, who is freezing in a Siberian labour camp because he dared to speak out in favour of human rights. We owe him a great debt and should do all that we can to help him in his time of need. As a symbol of our concern I suggest that each of us send a letter or greeting card

to Dr Kovalev at:

Pochtovy Yashchik

No $5110-1 \mathrm{BC}$

Moskva

USSR

This will let him know that he is not forgotten and will remind Soviet authorities that we have not forgotten our colleague. A blizzard of greeting cards would be an appropriate message at the end of this winter season.

Yours faithfully,

JAMES R. SPOTILA

Department of Biology,

State University College.

Buffalo, NY, USA. 